\title{
Therapies for cardiac light chain amyloidosis: an update
}

Alberto Aimo, ${ }^{1}$ Gabriele Buda, ${ }^{2}$ Marianna Fontana, ${ }^{3,4,5}$ Andrea Barison, ${ }^{6,7}$ Giuseppe Vergaro, ${ }^{6,7}$ Michele Emdin, ${ }^{6,7}$ Giampaolo Merlini. ${ }^{8,9}$

1. Cardiology Division, University of Pisa, Italy

2. Haematology Department, University of Pisa, Italy

3. Heart Hospital, London, United Kingdom

4. Institute of Cardiovascular Science, University College London, London, United Kingdom;

5. National Amyloidosis Centre, University College London, Royal Free Hospital, London, United Kingdom

6. Institute of Life Sciences, Scuola Superiore Sant'Anna, Pisa, Italy

7. Cardiology Division, Fondazione Toscana Gabriele Monasterio, Pisa, Italy

8. Amyloidosis Research and Treatment Centre, IRCCS Policlinico San Matteo, Pavia, Italy

9. Department of Molecular Medicine, University of Pavia, Italy

Disclosures: G.M. is consultant for Janssen, Millennium Takeda, Pfizer, Prothena, Ionis; the other Authors have no relationships relevant to the contents of this paper to disclose.

Word count: 4650 (text)

Short title: Therapies for cardiac AL amyloidosis

Address for correspondence:

Alberto Aimo, MD

Cardiology Division, University of Pisa.

Via Paradisa, 18. 56124, Pisa, Italy.

Phone +39 3477084391

Email: albertoaimo@libero.it, a.aimo@santannapisa.it 


\section{Abstract}

Light-chain (AL) amyloidosis is the most common type of systemic amyloidosis, affecting around 10 people per million per year. This serious disorder is characterized by the presence of a clone of bone marrow plasma cells that produces monoclonal light chains (LCs) of the $\kappa$ or predominantly $\lambda$ type. These amyloidogenic LCs undergo extracellular misfolding and aggregation into proteotoxic soluble oligomers and amyloid fibrils that deposit within tissues. The lethal consequences of AL amyloidosis are due to the toxic products (the LCs) and not to the malignant behaviour of the plasma cell clone. Almost $80 \%$ of patients with AL amyloidosis have some degree of cardiac involvement, manifesting as heart failure (HF), and carrying a particularly poor prognosis.

The past decade has seen major advances in the treatment of AL amyloidosis, and a rapidly fatal disease has become a treatable and possibly curable condition. The number of therapeutic options is rapidly expanding, offering hope to address currently unmet needs (most notably, the treatment of frail patients). The treatment of $\mathrm{AL}$ amyloidosis consists in a combination of agents targeting multiple steps of the amyloid cascade, associated with effective HF management, and there is ground for hope for dramatically improving the outcome in the near future.

In the present review we will summarize our current knowledge on therapy for cardiac AL amyloidosis, targeting clinical cardiologists involved in the care of this serious disorder.

Word count (abstract): 229

Keywords: AL amyloidosis, heart, therapies. 


\section{Introduction}

Light-chain (AL) amyloidosis is the most common type of systemic amyloidosis,[1] affecting around 10 people per million per year, approximately 5000 new patients in the European Union.[2,3] This often fatal disorder is characterized by the presence of a clone of bone marrow plasma cells that produces monoclonal light chains (LCs) of the $\kappa$ or predominantly $\lambda$ type.[2] These amyloidogenic LCs undergo extracellular misfolding and aggregation into proteotoxic soluble oligomers and amyloid fibrils that deposit within tissues. The lethal consequences of AL amyloidosis are due to the toxic products (the LCs), and not to the malignant behaviour of the plasma cell clone.[2] The clinical presentation is heterogeneous depending on organ involvement (most commonly heart and kidney, gastrointestinal tract, autonomous or peripheral nervous system and soft tissues).[4]

Almost $80 \%$ of patients with AL amyloidosis have some degree of cardiac involvement, manifesting as heart failure (HF), and carrying a particularly poor prognosis.[2,5] Indeed, when categorizing patients with $\mathrm{AL}$ amyloidosis according to N-terminal fraction of pro-B-type natriuretic peptide (NT-proBNP; cut-off $332 \mathrm{ng} / \mathrm{L}$ ) and cardiac troponin I (cTnI; cut-off $100 \mathrm{ng} / \mathrm{L}$ ), survival progressively decreased from stage I (both biomarkers below cut-offs) to stage II (only one biomarker increased), and to stage III (both biomarkers increased); patients with stage IIIb (NTproBNP $>8500 \mathrm{ng} / \mathrm{L}, 20 \%$ of patients) had a dismal prognosis, with median survival between 4 and 7 months.[6,7,8] Cardiac involvement at baseline is a major determinant of survival, and cardiac response to treatment (defined as $>30 \%$ and $>300 \mathrm{ng} / \mathrm{L}$ decrease in NT-proBNP when baseline NTproBNP is $\geq 650 \mathrm{ng} / \mathrm{L}$ )[9] is a powerful predictor of prognosis. With regard to the hematologic response, it can be classified as complete response (normal free LC - FLC - ratio and negative serum and urine immunofixation), very good partial response (difference between involved and uninvolved FLCs - dFLC $<40 \mathrm{mg} / \mathrm{L}$ ), partial response (dFLC decrease > 50\%), and no response.[9] 
Hematologic and cardiac responses predict survival as early as 3 months after treatment initiation.[9]

Therapeutic goals in cardiac AL amyloidosis are rapid elimination of the amyloid precursor, removal of fibrils, and effective management of HF (Figure 1). The research on this field is rapidly expanding, and many drugs and regimens have been proposed over the last years. In the present review we will summarize our current knowledge on therapy for cardiac AL amyloidosis, targeting clinical cardiologists involved in the care of this serious disorder, as well as cardiologists with expertise in heart failure or cardio-oncology.

\section{Therapies targeting the plasma cells: at the root of the problem}

Chemotherapy targeting the underlying plasma cell dyscrasia has changed considerably in the past decade, with markedly improved response rates and prolonged survival. Since AL amyloidosis is a rare disease, treatment recommendations rely mostly on phase 2 studies or retrospective analyses, and only a few randomized phase 3 studies have been carried out.[10,11] Chemotherapy for AL amyloidosis is based on regimens used for the treatment of multiple myeloma (MM), with adaptations in terms of dose and schedule.[12]

High-dose melphalan (HDM) with autologous stem cell transplantation (ASCT) was introduced in the care of AL amyloidosis by the Boston Group,[13] and is now considered the treatment of choice for approximately $20 \%$ of patients with good functional status without severe cardiac and renal involvement.[14] Indeed, ASCT is the most cytotoxic therapy against plasma cells, resulting in high response rates and the potential to avoid ongoing chemotherapy.[14] Careful selection of candidates to ASCT, especially with regard to cardiac involvement, is mandatory because of the high transplant-related mortality. A prospective, randomized, phase 3 trial comparing oral melphalan plus dexamethasone (MDex) vs. HDM with ASCT did not show a superiority of ASCT.[14] In a retrospective, multicentre analysis of 1536 patients with AL amyloidosis undergoing ASCT from 1995 to 2012, mortality at 30 and 100 days declined progressively, and 
overall survival improved.[15] Currently, a hematological response is achievable in more than 70\% of patients, and complete response in approximately 30 to $40 \%$.[16] The reported 10-year survival is about $40 \% .[17,18]$ When this therapeutic approach is chosen, close cardiologic evaluation is essential because stem cell collection is often associated with fluid retention and hypotension, and atrial arrhythmias may occur following chemotherapy.[19] Furthermore, even steroid treatment may promote fluid retention, as well as requiring careful titration. In general, it has been recommended that cardiologists with expertise in AL amyloidosis are involved during the chemotherapy treatment, and visit patients at frequent intervals throughout chemotherapy to adjust concomitant medications.[19]

Oral MDex is a very effective and well tolerated regimen that for several years has been the standard of care for patients not eligible to ASCT.[20] A recent update of the outcome of this regimen showed an overall median survival of 7.4 years.[21] The hematologic response rate was $76 \%$, with $31 \%$ of patients obtaining complete response, with $37 \%$ cardiac response and $24 \%$ kidney response, thus confirming the efficacy of this regimen.[21]

The degradation of cellular proteins is a tightly regulated and complex process that plays a central role in regulating cellular function and maintaining homoeostasis in every eukaryotic cell.[22] The ubiquitin-proteasome pathway represents the major pathway for intracellular protein degradation.[22] More than $80 \%$ of cellular proteins are degraded through this pathway, including those involved in the regulation of numerous cellular and physiological functions, such as cell cycle, apoptosis, transcription, DNA repair, protein quality control and antigens.[22] Proteasome inhibitors (PIs) block the proteasome either reversibly or irreversibly, causing downstream effects that can be summarized as follows: upregulation of proapoptotic protein expression, downregulation of several apoptosis inhibitors and proteins involved in DNA repair and activation of the unfolded protein response.[23] PIs also affect cell microenvironment, including inhibition of cytokine secretion, suppression of adhesion molecule expression and inhibition of angiogenesis.[23] 
The introduction of proteasome inhibitors has represented a major breakthrough in the care of AL amyloidosis. Bortezomib is a reversible inhibitor of the proteasome and has shown to rapidly reduce the concentration of amyloid light chains, as a single agent,[24] and in combination with dexamethasone and alkylating agents. As detailed in a recent review,[23] several studies have confirmed the efficacy of bortezomib as a single agent or combined with dexamethasone (VD regimen), also in terms of cardiac response (up to $29 \%$ of patients), with a good safety profile. In particular, the drug is generally well-tolerated in patients with cardiac amyloidosis; specifically, bortezomib cardiotoxicity has been reported, but appears to be rare.[25,26] The combination of cyclophosphamide and VD (CVD) is now a commonly used frontline therapy in AL amyloidosis.[23] Due to its rapidity of action, bortezomib-based regimens are now standard of care for non-transplant eligible patients. They were reported to be effective even in patients with advanced cardiac involvement.[27] Finally, the VD combination has been assessed as induction therapy before HDM with ASCT,[28, 29, 30] or as consolidation therapy after HDM and ASCT.[31,32] All these options proved feasible, well tolerated, and effective in extending survival and increasing cardiac response rates.[28-32] Finally, it is worth noting that bortezomib-based regimes can render about $30 \%$ of ineligible transplant patients capable of undergoing transplant.[33]

The second-generation oral proteasome inhibitor ixazomib has been tested in a phase $1 / 2$ trial in 27 relapsed/refractory patients with AL amyloidosis producing a hematologic response in 52\% of patients and organ responses in 56\% patients (5 cardiac, 5 renal).[34] A randomized phase 3 trial is currently underway, comparing ixazomib with physician's best choice.[35] Finally, a phase 1/2 study assessing safety and efficacy of a second-generation proteasome inhibitor, carfilzomib, in relapsed/refractory AL amyloidosis, showed a $63 \%$ response rate, but also significant cardiopulmonary toxicities in $36 \%$ of patients. In particular, the grade $3 / 4$ adverse effects were hypoxia, lung infection, chest pain, hypotension, hypertension, systolic dysfunction, and symptomatic ventricular tachycardia.[36] 
Thalidomide, lenalidomide and pomalidomide represent a group of agents that have shown good clinical efficacy in the treatment of AL amyloidosis.[37] Their mechanism of action is incompletely understood, and seems to include anti-angiogenic, anti-proliferative, and immunomodulatory effects.[38] These drugs are used mostly in the setting of relapsed or refractory disease, but may also be part of initial therapy.[19] Thalidomide in combination with other drugs is effective, but causes significant toxicity, especially neurotoxicity, and therefore should not be used for the treatment of AL amyloidosis.[39] Lenalidomide has shown a good toxicity profile, although caution should be used in patients with renal failure.[19,40] An increase in natriuretic peptide levels is frequently observed during treatment with lenalidomide, even when hematologic improvement in achieved, and in the absence of a demonstrable worsening in cardiac function.[41] Pomalidomide has been proven highly effective in a phase 2 trial,[42] has a better safety profile compared to all immunomodulatory agents, and is therefore becoming a promising therapeutic tool for the treatment of AL amyloidosis.[18]

\section{Novel approaches targeting the plasma cell}

While upfront LC suppressive therapy yields high hematologic overall response rates, the majority of patients do not achieve a complete hematologic response to therapy allowing ongoing toxic amyloid deposition.[43] Improvement in involved organ function is even less common, and almost all patients eventually experience a relapse requiring additional LC suppressive therapy.[43] These considerations justify the ongoing search for novel therapeutic strategies.

Bendamustine is an alkylating agent, and its mechanism of action consists in disruption of DNA replication. This drug is used for the treatment of several hematologic disorders, including MM and Waldenström macroglobulinemia.[44] In a recent retrospective analysis on 125 patients, often heavily pre-treated, the combination of bendamustine and prednisone appeared well tolerated, and a hematologic response was associated with a survival benefit.[45] Notably, only 58\% of these patients had cardiac involvement. A cardiac response was observed in just 6 out of 48 patients with 
evaluable NT-proBNP (13\%), and cardiac failure as drug-related adverse event was reported in $2 \%$ of patients.[45] The ongoing phase II trial on bendamustine and dexamethasone in patients with relapsed AL amyloidosis [46] will help clarify the safety and efficacy of this drug regimen in advanced disease stages.

Daratumumab is a human IgG1k monoclonal antibody targeting the CD38 surface antigen on plasma cells, which has been approved in 2015 by the Food and Drug Administration for the treatment of patients with relapsed or refractory MM.[47] Clonal plasma cells in AL express surface CD38, providing a rationale for the use of daratumumab in AL amyloidosis.[47] After a report of safety and efficacy in 2 patients with advanced, multisystem disease,[48] a recent study on 25 patients (72\% with cardiac involvement) found that daratumumab, administered in the dose and schedule approved for MM, rapidly lowers circulating LCs, without significant adverse effects.[49] In particular, daratumumab was well tolerated even among patients with advanced cardiac AL involvement.[49]

In order to block the production of amyloid precursor proteins, small interfering RNAs (siRNAs) have been considered. siRNAs are non-coding RNA molecules that bind messenger RNA (mRNA) blocking its translation into a protein sequence and/or promoting mRNA degradation.[50] siRNAs specific for a commonly encountered LC sequence in AL amyloidosis caused a significant reduction in LC production in plasmacytomas secreting human amyloidogenic LCs.[51] Several issues remain to be solved before assessing siRNAs in clinical trials. Most notably, plasma half-life should be extended, and a delivery system that specifically targets plasma cells in the bone marrow should be found.[51]

A possible further therapeutic approach is the activation of the unfolded protein response, which was identified as a process whose activation selectively attenuates the secretion of destabilized, amyloidogenic LCs, while not affecting the production of non-amyloidogenic LCs.[52] In cell cultures, expression of one or both transcription factors X-box binding protein 1 (XBP1) or activating transcription factor 6 (ATF6) reduces the secretion and ultimately extracellular 
aggregation of LCs by inducing protein degradation (XBP1) or intracellular retention (ATF6); [52] the latter mechanism could be cytotoxic or make the cell more vulnerable to chemotherapy.[52] The possibility of reducing the secretion of abnormal LCs has been confirmed,[53] and has prompted the search for small molecules able to mimic the activity of ATF6.[54]

Another interesting perspective is represented by the use of venetoclax in patients with AL amyloidosis harboring the translocation $\mathrm{t}(11 ; 14)$. In a patient achieving only a partial response with cyclophosphamide, bortezomib and dexamethasone, adding venetoclax to bortezomib and dexamethasone caused a complete response.[55] Since $t(11 ; 14)$ is the most common cytogenetic abnormality in AL amyloidosis, this approach could represent a major advance in the treatment of these patients.[55]

\section{Blockade of aggregation or proteotoxicity of tissue light chains}

In addition to the physical effects of AL fibril formation, amyloidogenic LCs are cardiotoxic per se, reducing contractility in cardiac myocytes,[56] causing early death in zebrafish,[57] and reducing pharyngeal contractility in Caenorhabditis elegans.[58] Therapeutic approaches targeting deposited LCs thus aim at relieving their cardiotoxic effects and preventing the formation of amyloid fibres.

The antibiotic doxycycline seems to be active on both fronts. Its polycyclic conjugated structure displays a close similarity with that of the anthracycline 4'-iodo-4'-deoxydoxorubicin, which emerged as an inhibitor of amyloid fibril formation.[59,60] Doxycycline has also been shown to inhibit amyloid deposition in a mouse model of $\mathrm{AL}$ amyloidosis, and to disrupt LC fibres in vitro.[61] In a preliminary report, patients with systemic AL amyloidosis receiving doxycycline as antimicrobial prophylaxis after stem cell transplantation had significantly better survival compared to penicillin.[62] A recent retrospective study compared 30 patients with cardiac AL amyloidosis receiving doxycycline (100 $\mathrm{mg}$ twice daily for a median duration of 6 months) plus standard chemotherapy vs. 73 matched controls.[63] On an intention-to-treat basis, more patients in the doxycycline group achieved partial or complete hematologic response, and cardiac response, with 
significant improvement in survival.[63] As of March 2018, three trials on doxycycline in AL amyloidosis are underway, and there is one completed trial on patients "with measurable amyloid disease" (i.e. not only AL amyloidosis). In this last case, the population size is probably too small (25 patients starting, 14 completing) and heterogeneous to yield any meaningful result.[64] With regard to the other studies, the Doxycycline to Upgrade Organ Response in Light Chain (AL) Amyloidosis (DUAL) trial is a phase II open label study of oral doxycycline administered together with plasma cell directed therapy;[65] a randomized phase II/III trial will assess doxycycline vs. standard supportive therapy in newly-diagnosed cardiac al amyloidosis patients undergoing bortezomib-based therapy;[66] finally, a randomized controlled trial will evaluate doxycycline as adjunctive to bortezomib, cyclophosphamide and dexamethasone in newly diagnosed patients.[67]

Epigallocatechin-3-gallate $(E G C G)$ is a polyphenol, which is abundant in green tea, and is credited with potent antioxidant properties. EGCG proved able to redirect amyloidogenic polypeptides into unstructured oligomers, thus preventing amyloid fibre formation in vitro.[68,69] In an observational study, 11 patients with cardiac AL amyloidosis "started to drink large daily amounts of green tea (1.5-2 L/daily)," and displayed a decrease $\geq 2 \mathrm{~mm}$ in their interventricular wall thickness (IWT).[70] Despite the unorthodox approach to treatment, the promising results led to a phase II study on 57 patients with AL amyloidosis.[71] Among patients with cardiac involvement $(n=24,42 \%)$, no significant differences were observed between those on EGCG $(n=15)$ and those receiving standard chemotherapy only $(n=9)$ in biomarker levels (troponin T, NT-proBNP), as well as IWT or native T1, over a 6-month follow-up.64 The drug, administered three times per day by capsules (corresponding to $630 \mathrm{mg}$ EGCG three times per day), was well tolerated.[71] The findings of a completed study,[72] and an ongoing trial [73] will further clarify the therapeutic potential of EGCG.

As stated above, LC accumulation promotes contractile dysfunction and apoptosis through a p38 $\alpha$ - mitogen-activated protein kinase (MAPK) pathway, and treatment of cultured cardiomyocytes with SB203580, a selective p38 MAPK inhibitor, significantly attenuated AL-LC- 
induced oxidative stress, cellular dysfunction, and apoptosis.[74] To our knowledge, modulation of this pathway has not been considered as a possible therapeutic approach so far. Similarly, dysregulated autophagic flux seems to contribute to LC-mediated cardiotoxicity, and restoration of normal autophagic mechanisms by rapamycin (also known as sirolimus) protected against contractile dysfunction and cell death at the cellular and organ level and prolonged survival in a zebrafish model of amyloid cardiotoxicity.[74] Nevertheless, modulators of cell autophagy have not been evaluated so far as possible therapies for AL amyloidosis.

\section{Amyloid fibres: making the insoluble soluble}

Together to the blockade of amyloidogenic LC production, rapid and effective elimination of amyloid deposits from tissues would be important to maintain or restore vital organ function.[75] On the contrary, even when the plasma cell dyscrasia is treated effectively, amyloid regression often does not occur, with persistent organ dysfunction. Indeed, systemic amyloid deposits are characteristically acellular with no surrounding inflammatory reaction.[76] Therefore, attempts have been made to elicit an immune response against amyloid fibres.

Serum amyloid P component (SAP) is an invariant, normal, non-fibrillar plasma glycoprotein. SAP binds avidly but reversibly to all types of amyloid fibrils, and thus is specifically concentrated in all amyloid deposits. A small-molecule drug, (R)-1-[6-[(R)-2-carboxy-pyrrolidin-1-yl]-6-oxohexanoyl]pyrrolidine-2-carboxylic acid (CPHPC), specifically binds to SAP; it swiftly depletes almost all circulating SAP and some, but not all, SAP from tissue amyloid deposits.[77,78] In mice with systemic amyloid A (AA) amyloidosis that are transgenic for human SAP, antibodies targeting human SAP administered after CPHPC, bind to residual amyloid-bound SAP and trigger clearance of the deposits.[79] Similar findings have been reported in an open-label, single-dose-escalation, phase 1 trial involving 15 patients with systemic amyloidosis ( $\mathrm{n}=8,53 \%$, with AL amyloidosis).[80] After CPHPC administration, a fully humanized monoclonal anti-SAP antibody was infused. At 6 weeks, patients who had received a sufficient dose of antibody in relation to their amyloid load had 
decreased liver stiffness, as measured with the use of transient elastography. These patients also had improvements in liver function in association with a substantial reduction in hepatic amyloid load, as shown by means of SAP scintigraphy and measurement of extracellular volume by magnetic resonance imaging. A reduction in kidney amyloid load and shrinkage of an amyloid-laden lymph node were also observed.[80] As per study protocol, patients with AL amyloidosis received a dose per patient based on the amyloid load, which was estimated through ${ }^{123}$ I-SAP scintigraphy; this dose was much higher than other patients.[80] The results were also greater, with major changes in amyloid load and more frequent improvement in SAP scan, together with higher frequency of an acute phase response, in line with a greater activation of inflammatory mechanisms.[80] The treatment displayed also a goof safety profile.[80] On the other hand, a major limitation of this ground-breaking study is the enrolment of patients in good functional status and with no overt cardiac involvement.[80] A very recent study assessed this therapeutic approach (up to three cycles of CPHPC followed by anti-SAP antibodies) on 6 patients with cardiac amyloidosis, reporting no adverse cardiac events and a reduction of $17 \%$ in left ventricular mass by cardiac MRI in a patient, but also no significant effects on outcome.[81] Overall, the safety and efficacy of a treatment with anti-SAP antibody for cardiac amyloidosis remain to be further investigated.

Passive immunotherapy with antibodies against specific epitopes of the misfolded LC proteins have been developed. NEODO01, a humanized form of murine monoclonal antibody 2A4, was shown to react with both soluble and insoluble LC aggregates derived from samples from patients with AL while sparing normally folded LCs.[82] In vivo, this antibody promoted AL amyloid clearance in a mouse amyloidoma by engaging phagocytes.[82] The interim results of the first-inhuman phase I/II study of NEOD001 in patients with AL amyloidosis were published in 2016.[83] Patients who had completed at least one anti-plasma cell-directed therapy achieving at least partial hematologic response, but displaying persistent organ dysfunction, received intravenous infusions of NEOD001 every 28 days, at dose levels up to $24 \mathrm{mg} / \mathrm{kg}(3+3$ study design).[83] The emerging recommended dose was $24 \mathrm{mg} / \mathrm{kg}$.[83] Cardiac evaluable patients were those (14 out of the 27 
patients enrolled, 52\%) having baseline NT-proBNP $\geq 650 \mathrm{ng} / \mathrm{L}$, and cardiac response was defined as $>30 \%$ and $300 \mathrm{ng} / \mathrm{L}$ decrease in NT-proBNP.76 Eight patients $(57 \%)$ met the criteria for cardiac response, and six (43\%) had stable disease. The drug was well tolerated, with no major adverse events.[83] Notably, these conclusions cannot be extended to patients with more severe cardiac involvement, as patients with NT-proBNP levels higher than $5000 \mathrm{ng} / \mathrm{L}$ were not enrolled.[83] These results prompted the initiation of the phase III VITAL Amyloidosis Study (NCT02312206), a multi-centre, international, event-driven, randomized, double-blind, placebo-controlled, two-arm efficacy and safety study in subjects newly diagnosed with AL amyloidosis. This study should have given insight on cardiac response, assessed as NT-proBNP variations, but also in terms of hard endpoints (all-cause and cardiac death, cardiac hospitalization), functional capacity (change in 6minute walking distance), and symptoms (Kansas City Cardiomyopathy Questionnaire).[ 84] However, following the negative results of another phase $2 b$ study (the PRONTO trial), on April 23, 2018 the producing company has announced its decision to discontinue all development of NEOD001, including the VITAL study and the open label extension studies.[85]

\section{Management of cardiac involvement}

$\mathrm{HF}$ in cardiac amyloidosis poses specific therapeutic challenges because of patient frailty, multiorgan involvement and specific pathophysiology, resulting in different response to treatment.[19] The traditional therapeutic paradigm of HF cannot be simply translated to cardiac amyloidosis, as angiotensin converting enzyme inhibitors/angiotensin receptor blockers, beta blockers, and mineralocorticoid receptor antagonists are often poorly tolerated because of hypotension, renal insufficiency, or other contraindications. Therefore, a strategy of neurohormonal antagonism requires slow drug up-titration and close patient monitoring. Relief from congestion usually requires loop diuretics; bioavailable loop diuretics (torsemide and bumetanide) are preferable to furosemide, especially when gut edema is expected because of right HF. Loop diuretics can be usefully combined with spironolactone.[19] Non-dihydropyridine calcium channel 
blockers must be avoided as they may worsen congestive HF. Moreover, digoxin is traditionally seen as not effective for HF treatment, and yielding a risk of toxicity within the therapeutic range because of altered binding of digoxin molecules to the amyloid-laden heart.[86] On the other hand, a very recent retrospective analysis on 107 patients with AL concluded that digoxin treatment has an acceptable safety profile provided when low doses are administered, and drug concentration, electrolytes and renal function are closely monitored.[87]

As a result of amyloid infiltration of the atrial walls and atrial enlargement because of ventricular diastolic dysfunction, there is a higher incidence of atrial fibrillation, flutter, or tachycardia. These arrhythmias are often poorly tolerated because of greater reliance on atrial contribution to ventricular filling, and possibly a high ventricular response. Catheter ablation may be difficult because of the extensive atrial involvement, and the recurrence rate is high.[88] The two most commonly used antiarrhythmics for patients with AL amyloidosis who have atrial fibrillation are amiodarone and dofetilide. These agents do not have significant negative inotropic effects and thus are preferred. Indeed, antiarrhythmic agents with a negative inotropic or chronotropic effect should be avoided, although beta-blockers may be used cautiously.[19] Finally, the use of digoxin for rate control should be avoided, as it yields a significant risk of toxicity (see above).

Anticoagulation with either warfarin or the novel oral anticoagulants can usually be safely administered to patients with AL amyloidosis. Its use has been advocated for any atrial arrhythmia, and possibly also if the patient is in sinus rhythm, when there is echocardiographic evidence of left atrial mechanical dysfunction, because thrombus formation and embolization may occur in these patients.[19]

Ventricular arrhythmias are relatively uncommon in AL amyloidosis, and sudden death is most often due to profound bradycardia or pulseless electrical activity,[89] usually in patients with severe amyloid cardiomyopathy. The possibility to influence the natural history of cardiac AL amyloidosis through defibrillator implantation seems limited,[90,91] and even patients deemed at higher risk because of a history of syncope and/or ventricular ectopic beats did not derive a survival benefit 
from ICD.[92] It has been proposed to consider ICD therapy when patients 1) do not have New York Heart Association (NYHA) class IV symptoms or life expectancy <1 year, 2) have a history of non-posturally mediated syncope or demonstrated non-sustained ventricular tachycardia (NSVT) at telemetry monitoring.[93] Alternatively, ICD implantation followed by anti-arrhythmic therapy has been proposed for patients 1) in NYHA class I-III, NT-proBNP $<8500 \mathrm{ng} / \mathrm{L}$ and systolic blood pressure $>90 \mathrm{mmHg}$, and 2) with history of recurrent cardiac syncope or NSVT.[91] However, these algorithms rely on expert opinion, and evidence from clinical trials or registries is warranted. Finally, the finding that bradyarrhythmias may herald terminal cardiac decompensation has suggested the possible benefit from prophylactic pacemaker implantation, [94] but to our knowledge this approach has never been evaluated so far.

LVAD implantation is technically feasible, but is burdened by high morbidity and poor outcome, therefore it should not be viewed as a viable option.[95] Another therapeutic option is orthotopic heart transplantation (OHT), which should be considered in patients aged $<65$ years, at high cardiac risk (Mayo stage IIIb), and without significant extra-cardiac amyloidosis.[96,97] With regard to this last point, careful evaluation for organ involvement prior to OHT is recommended,[98] and most patients with AL amyloidosis have multisystem disease, thus not being candidates. For patients undergoing OHT, the best tolerated hematologic regimen should be started immediately after transplantation to avoid progression of the systemic disease with amyloid infiltration of the transplanted heart, and ASCT should be considered.[19] The outcomes were poor before the introduction of proteasome inhibitors, but have improved in the following years.[98]

\section{Management of cardiac amyloidosis: an overview}

The treatment of cardiac AL amyloidosis relies on a combination of therapies that globally aim at controlling the hematologic disorder and relieving the ongoing cardiac damage. Patient's clinical status is a crucial determinant of prognosis, and influences also the therapeutic choices. A classification system based on biomarker levels, age, renal function, and functional status has been 
proposed (Figure 2).[99,100] "Fit" patients should receive high-dose melphalan and autologous stem cell transplantation (HDM-ASCT), hematologic response is achieved in approximately $75 \%$ of cases, and cardiac response in 30-40\%. Several options are available for "intermediate-fit" patients: full-dose chemotherapy, bortezomib-based regimens (bortezomib, cyclophosphamide and dexamethasone - CyBorD, bortezomib, melphalan and dexamethasone - BorMDex), or melphalandexamethasone (MDex). Hematologic response is reached in $65 \%$ of patients, and cardiac response in $30 \%$. Finally, therapeutic options for frail patients include cautious escalation of chemotherapy (bortezomib-dexamethasone), heart transplantation, left ventricular assist device (LVAD) implantation, or experimental approaches. Rates of hematologic response and cardiac response are $40 \%$ and 5-10\%, respectively, configuring an unmet need for safe and effective therapy for this patient population. $[99,100]$

Despite the apparent simplicity of this algorithm, tailoring the treatment on each individual patient may be a daunting task, and can rely on limited supporting evidence. Therefore, a close collaboration among cardiologists, hematologists, nephrologists, and other specialists (according to the individual disease phenotype) is required in order to choose the best treatment strategy. Last but not least, cardiologists should consider cardiac AL amyloidosis among differential diagnoses, and hematologists should consider the possibility of a cardiac involvement in patients with plasma cell dyscrasias. Indeed, early diagnosis means better functional status, possibility to adopt a more aggressive therapeutic approach, and ultimately greater survival.

\section{Conclusions}

The past decade has seen major advances in the treatment of AL amyloidosis, and a rapidly fatal disease has become a treatable and possibly curable condition. The number of therapeutic options is rapidly expanding (Table 1), offering hope to address currently unmet needs (most notably, the treatment of frail patients, such as those with overt cardiac involvement). In the near future the treatment of AL amyloidosis will probably consist in a combination of agents targeting multiple 
steps of the amyloid cascade, and there is ground for hope for dramatically improving the outcome in the near future. Nonetheless, this goal will not be achieved unless cardiologists realize greater awareness of cardiac AL amyloidosis and the options for its treatment, allowing early diagnosis and proper management of this condition. 


\section{Figure legends}

Figure 1. Targets for treatment in cardiac light-chain (AL) amyloidosis, and possible approaches.

ASCT

Bortezomib-based

Immunomodulating drugs

MDex

Bendamustine

Daratumumab

Venetoclax (?)
Loop diuretics

ACEi/ARB, BB, MRA (?)

Amiodarone

Anticoagulants

ICD/PM (?)

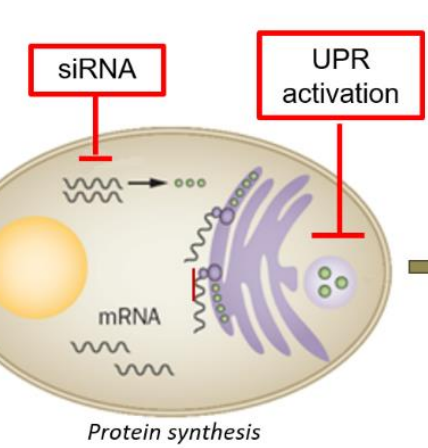

Protein synthesis
Doxycycline EGCG p38 MAPK inhibitors Rapamycin

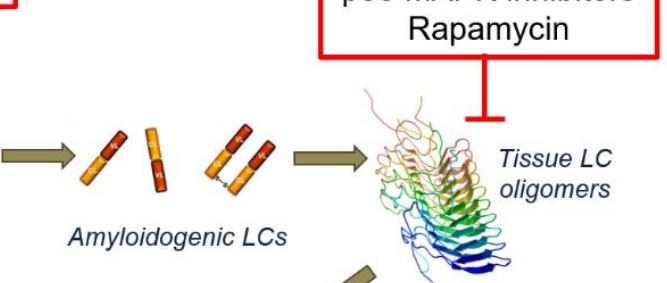

The therapeutic approaches are discussed extensively in the text. ACEi/ARB, angiotensin converting enzyme inhibitor/angiotensin receptor blocker; ASCT, autologous stem cell transplantation; BB, beta-blocker; EGCG, epigallocatechin-3-gallate; HF, heart failure; ICD, implantable cardioverter defibrillator; LCs, light chains; mAb, monoclonal antibody; MAPK, mitogen-activated protein kinase; MRA, mineralocorticoid receptor antagonist; PM, pacemaker; SAP, serum amyloid P component; siRNA, small interfering RNAs; UPR, unfolded protein response. 
Figure 2. Choice of treatment for cardiac AL amyloidosis based on patient risk stratification.

Patient category

Fit patients
( 20\%)
- NT-proBNP <5000 ng/L
- Troponin T<60 ng/L
- Age $<70$ years
- Creatinine $<1.8 \mathrm{mg} / \mathrm{dL}$
Intermediate-fit patients
( 60\%)
- NT-proBNP $\leq 8500 \mathrm{ng} / \mathrm{L}$
- ECOG 2
- NYHA I-II
Frail patients
( 20\%)
- NT-proBNP $>8500$ ng/L
- SBP <100 mmHg
- Marked coagulopathy
- ECOG 4
- NYHA III-IV

Therapy

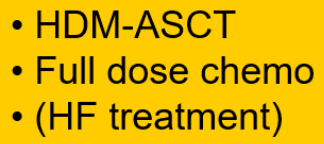

- HDM-ASCT

- Full dose chemo

- (HF treatment)

Outcome

Hem. response $75 \%$

Complete response 30 -

$40 \%$

Cardiac response 30 $40 \%$

Hem. response $65 \%$

Complete response 20-

$30 \%$

Cardiac response $30 \%$

Hem. response $40 \%$

Complete response $15 \%$

Cardiac response $5-10 \%$

Haematologic response: complete response (normal FLC ratio, negative immunofixation), very good partial response (difference between involved and uninvolved FLCs - dFLC $<40 \mathrm{mg} / \mathrm{L}$ ), partial response (dFLC decrease $>50 \%$ ), no response.

Cardiac response: $>30 \%$ and $>300 \mathrm{ng} / \mathrm{L}$ decrease in NT-proBNP.

All the criteria used to define the subgroups are required. The hematologic response to treatment can be classified as complete response (normal free LC - FLC - ratio and negative serum and urine immunofixation), very good partial response (difference between involved and uninvolved FLCs $\mathrm{dFLC}<40 \mathrm{mg} / \mathrm{L}$ ), partial response (dFLC decrease $>50 \%$ ), and no response. Cardiac response has been defined as $>30 \%$ and $>300 \mathrm{ng} / \mathrm{L}$ decrease in NT-proBNP (if baseline NT-proBNP is $\geq 650$ ng/L). BorMDex, bortezomib, melphalan and dexamethasone; CT, chemotherapy; CyBorD, bortezomib, cyclophosphamide and dexamethasone; ECOG, Eastern Cooperative Oncology Group; HDM-ASCT, high-dose melphalan and autologous stem cell transplantation; ICD, implantable cardioverter defibrillator; LVAD, left ventricular assist device; MDex, melphalan-dexamethasone; NT-proBNP, N-terminal fraction of pro-B-type natriuretic peptide; NYHA, New York Heart Association; SBP, systolic blood pressure.

From: Merlini et al., 2014;[99] Le Bras et al., 2017.[100] 
Table 1. Therapies for cardiac light chain (AL) amyloidosis.

\begin{tabular}{|c|c|c|c|}
\hline Targets & Therapies & Notes & References \\
\hline \multirow[t]{7}{*}{ Plasma cells } & High-dose melphalan with ASCT & $\begin{array}{l}\text { Treatment of choice for patients with good functional status without severe cardiac } \\
\text { and renal involvement }\end{array}$ & [14-19] \\
\hline & Melphalan-dexamethasone & Effective and well tolerated & {$[20-21]$} \\
\hline & Proteasome inhibitors & $\begin{array}{l}\text { - Bortezomib: safe and effective; bortezomib-based regimens: standard of care for } \\
\text { patients not eligible to ASCT. } \\
\text { - Ixazomib }\end{array}$ & [22-36] \\
\hline & $\begin{array}{l}\text { Thalidomide, lenalidomide and } \\
\text { pomalidomide }\end{array}$ & $\begin{array}{l}\text { Often used for relapsed or refractory disease. Increase in NP levels during } \\
\text { treatment with pomalidomide }\end{array}$ & {$[37-42]$} \\
\hline & Bendamustine & $\begin{array}{l}\text { Bendamustine and prednisone: well tolerated and effective in heavily pre-treated } \\
\text { patients. } \\
\text { Bendamustine and dexamethasone: clinical trial underway }\end{array}$ & {$[45-46]$} \\
\hline & Daratumumab & $\begin{array}{l}\text { Effective in reducing circulating LCs, well tolerated even with advanced cardiac } \\
\text { involvement }\end{array}$ & [47-49] \\
\hline & $\begin{array}{l}\text { Experimental approaches (small } \\
\text { interfering RNAs, activation of the }\end{array}$ & Under evaluation & {$[50-55]$} \\
\hline
\end{tabular}




\begin{tabular}{|c|c|c|c|}
\hline & $\begin{array}{l}\text { unfolded protein response, } \\
\text { venetoclax) }\end{array}$ & & \\
\hline \multirow{3}{*}{$\begin{array}{l}\text { Tissue light } \\
\text { chains }\end{array}$} & Doxycycline & Disrupts LC fibers in vitro. Promising approach, clinical trials underway & [59-67] \\
\hline & Epigallocatechin-3-gallate & Prevents amyloid formation in vitro. Clinical trials underway & [68-73] \\
\hline & $\begin{array}{l}\text { Experimental approaches (p38 } \\
\text { MAPK inhibitor, rapamycin) }\end{array}$ & Under evaluation & [74] \\
\hline \multirow[t]{2}{*}{$\begin{array}{l}\text { Amyloid } \\
\text { fibers }\end{array}$} & CPHPC + anti-SAP Abs & $\begin{array}{l}\text { - CPHPC depletes circulating SAP; Abs then bind to residual amyloid-bound SAP } \\
\text { and trigger clearance of the deposits } \\
\text { - Reduction in amyloid load, uncertain effects on outcome }\end{array}$ & [77-81] \\
\hline & NEOD001 & Ab targeting specific epitopes of misfolded LC proteins. Clinical trial underway & [82-84] \\
\hline \multirow{5}{*}{$\begin{array}{l}\text { Cardiac } \\
\text { involvement }\end{array}$} & ACEi/ARB, BB, MRA & Often poorly tolerated, to be used with caution & [19] \\
\hline & Loop diuretics & $\begin{array}{l}\text { Relieve congestion. Torsemide and bumetanide better absorbed than furosemide. } \\
\text { Possible combination with spironolactone. }\end{array}$ & [19] \\
\hline & Non-dihydropyridine CCBs & Contraindicated & [19] \\
\hline & Digoxin & Contraindicated (risk of toxicity) & {$[85]$} \\
\hline & Antiarrhythmic therapy & $\begin{array}{l}\text { Amiodarone, dofetilide preferred (no negative inotropic effects). BB may be used } \\
\text { cautiously. Digoxin: risk of toxicity }\end{array}$ & [19] \\
\hline
\end{tabular}




\begin{tabular}{|c|c|c|}
\hline Anticoagulation & For atrial fibrillation (plus other atrial arrhythmias) & [19] \\
\hline ICD & $\begin{array}{l}\text { Limited benefit, uncertain predictors of benefit. For patients who: 1) do not have } \\
\text { NYHA class IV symptoms or life expectancy <1 year, 2) have a history of non- } \\
\text { posturally mediated syncope or demonstrated NSVT }\end{array}$ & {$[88-92]$} \\
\hline PM & Never specifically evaluated & - \\
\hline LVAD & High morbidity and poor outcome & [93-94] \\
\hline Heart transplantation & $\begin{array}{l}\text { To be considered in patients aged }<65 \text { years at high cardiac risk (Mayo stage IIIb), } \\
\text { without significant extra-cardiac amyloidosis }\end{array}$ & {$[95-97]$} \\
\hline
\end{tabular}

ACEi/ARB, angiotensin converting enzyme inhibitor/angiotensin receptor blocker; ASCT, autologous stem cell transplantation; BB, beta-blockers; CCB, calcium channel blockers; CPHPC, (R)-1-[6-[(R)-2-carboxy-pyrrolidin-1-yl]-6-oxo-hexanoyl]pyrrolidine-2-carboxylic acid; ICD, implantable cardioverter defibrillator; LC, light chain; LVAD, left ventricular assist device; MAPK, mitogen-activated protein kinase; MRA, mineralocorticoid receptor antagonists; NSVT, non-sustained ventricular tachycardia. 


\section{References}

[1] Nienhuis HL, Bijzet J, Hazenberg BP. The prevalence and management of systemic amyloidosis in Western countries. Kidney Dis (Basel). 2016;2:10-9.

[2] Grogan M, Dispenzieri A. Natural history and therapy of AL cardiac amyloidosis. Heart Fail Rev 2015;20:155-62.

[3] Dispenzieri A, Merlini G. Immunoglobulin light chain systemic amyloidosis. Cancer Treat Res 2016;169:273-318.

[4] Merlini G, Bellotti V. Molecular mechanisms of amyloidosis. N Engl J Med 2003;349:583-96.

[5] Wechalekar AD, Gillmore JD, Hawkins PN. Systemic amyloidosis. Lancet 2016;387:2641-54.

[6] Dispenzieri A, Gertz MA, Kyle RA, Lacy MQ, Burritt MF, Therneau TM, Greipp PR, Witzig TE, Lust JA, Rajkumar SV, Fonseca R, Zeldenrust SR, McGregor CG, Jaffe AS. Serum cardiac troponins and N-terminal pro-brain natriuretic peptide: a staging system for primary systemic amyloidosis. J Clin Oncol 2004;22:3751-7.

[7] Wechalekar AD, Schonland SO, Kastritis E, Gillmore JD, Dimopoulos MA, Lane T, Foli A, Foard D, Milani P, Rannigan L, Hegenbart U, Hawkins PN, Merlini G, Palladini G. A European collaborative study of treatment outcomes in 346 patients with cardiac stage III AL amyloidosis. Blood 2013;121:3420-7.

[8] Kristen AV, Brokbals E, Aus dem Siepen F, Bauer R, Hein S, Aurich M, Riffel J, Behrens HM, Krüger S, Schirmacher P, Katus HA, Röcken C. Cardiac amyloid load: a prognostic and predictive biomarker in patients with light-chain amyloidosis. J Am Coll Cardiol 2016;68:1324.

[9] Palladini G, Dispenzieri A, Gertz MA, Kumar S, Wechalekar A, Hawkins PN, Schönland S, Hegenbart U, Comenzo R, Kastritis E, Dimopoulos MA, Jaccard A, Klersy C, Merlini G. New criteria for response to treatment in immunoglobulin light chain amyloidosis based on 
free light chain measurement and cardiac biomarkers: impact on survival outcomes. J Clin Oncol 2012;30:4541-9.

[10] Kyle RA, Gertz MA, Greipp PR, Witzig TE, Lust JA, Lacy MQ, Therneau TM. A trial of three regimens for primary amyloidosis: colchicine alone, melphalan and prednisone, and melphalan, prednisone, and colchicine. N Engl J Med 1997;336:1202-7.

[11] Jaccard A, Moreau P, Leblond V, Leleu X, Benboubker L, Hermine O, Recher C, Asli B, Lioure B, Royer B, Jardin F, Bridoux F, Grosbois B, Jaubert J, Piette JC, Ronco P, Quet F, Cogne M, Fermand JP; Myélome Autogreffe (MAG) and Intergroupe Francophone du Myélome (IFM) Intergroup. High-dose melphalan versus melphalan plus dexamethasone for AL amyloidosis. N Engl J Med 2007;357:1083-93.

[12] Kastritis E, Dimopoulos MA. Recent advances in the management of AL Amyloidosis. Br J Haematol 2016;172:170-86.

[13] Comenzo RL, Vosburgh E, Falk RH, Sanchorawala V, Reisinger J, Dubrey S, Dember LM, Berk JL, Akpek G, LaValley M, O'hara C, Arkin CF, Wright DG, Skinner M. Dose-intensive melphalan with blood stem-cell support for the treatment of AL (amyloid light-chain) amyloidosis: survival and responses in 25 patients. Blood 1998;91:3662-70.

[14] Gertz MA. Immunoglobulin light chain amyloidosis: 2014 update on diagnosis, prognosis, and treatment. Am J Hematol 2014;89:1132-1140.

[15] D'Souza A, Dispenzieri A, Wirk B, Zhang MJ, Huang J, Gertz MA, Kyle RA, Kumar S, Comenzo RL, Peter Gale R, Lazarus HM, Savani BN, Cornell RF, Weiss BM, Vogl DT, Freytes CO, Scott EC, Landau HJ, Moreb JS, Costa LJ, Ramanathan M, Callander NS, Kamble RT, Olsson RF, Ganguly S, Nishihori T, Kindwall-Keller TL, Wood WA, Mark TM, Hari P. Improved outcomes after autologous hematopoietic cell transplantation for light chain 
amyloidosis: a Center for International Blood and Marrow Transplant Research Study. J Clin Oncol 2015;33:3741-9.

[16] Dispenzieri A, Seenithamby K, Lacy MQ, Kumar SK, Buadi FK, Hayman SR, Dingli D, Litzow MR, Gastineau DA, Inwards DJ, Micallef IN, Ansell SM, Johnston PB, Porrata LF, Patnaik MM, Hogan WJ, Gertz MA. Patients with immunoglobulin light chain amyloidosis undergoing autologous stem cell transplantation have superior outcomes compared with patients with multiple myeloma: a retrospective review from a tertiary referral center. Bone Marrow Transplant 2013;48:1302-7.

[17] Cordes S, Dispenzieri A, Lacy MQ, Hayman SR, Buadi FK, Dingli D, Kumar SK, Hogan WJ, Gertz MA. Ten-year survival after autologous stem cell transplantation for immunoglobulin light chain amyloidosis. Cancer 2012;118:6105-9.

[18] Sanchorawala V, Sun F, Quillen K, Sloan JM, Berk JL, Seldin DC. Long-term outcome of patients with AL amyloidosis treated with high-dose melphalan and stem cell transplantation: 20-year experience. Blood 2015;126:2345-7.

[19] Falk RH, Alexander KM, Liao R, Dorbala S. AL (Light-Chain) Cardiac amyloidosis: a review of diagnosis and therapy. J Am Coll Cardiol 2016;68:1323-41.

[20] Palladini G, Perfetti V, Obici L, Caccialanza R, Semino A, Adami F, Cavallero G, Rustichelli R, Virga G, Merlini G. Association of melphalan and high-dose dexamethasone is effective and well tolerated in patients with AL (primary) amyloidosis who are ineligible for stem cell transplantation. Blood 2004;103:2936-8.

[21] Palladini G, Milani P, Foli A, Obici L, Lavatelli F, Nuvolone M, Caccialanza R, Perlini S, Merlini G. Oral melphalan and dexamethasone grants extended survival with minimal toxicity in AL amyloidosis: long-term results of a risk-adapted approach. Haematologica 2014;99:743-50. 
[22] Kubiczkova L, Pour L, Sedlarikova L, Hajek R, Sevcikova S. Proteasome inhibitors molecular basis and current perspectives in multiple myeloma. J Cell Mol Med 2014;18:94761.

[23] Jelinek T, Kryukova E, Kufova Z, Kryukov F, Hajek R. Proteasome inhibitors in AL amyloidosis: focus on mechanism of action and clinical activity. Hematol Oncol 2016 Sep 20. [Epub ahead of print]

[24] Reece DE, Sanchorawala V, Hegenbart U, Merlini G, Palladini G, Fermand JP, Vescio RA, Liu X, Elsayed YA, Cakana A, Comenzo RL; VELCADE CAN2007 Study Group. Weekly and twice-weekly bortezomib in patients with systemic AL amyloidosis: results of a phase 1 dose-escalation study. Blood 2009;114:1489-97.

[25] Cole DC, Frishman WH. Cardiovascular complications of proteasome inhibitors used in multiple myeloma. Cardiol Rev 2017 Dec 5 [Epub ahead of print]

[26] Bockorny M, Chakravarty S, Schulman P, Bockorny B, Bona R. Severe heart failure after bortezomib treatment in a patient with multiple myeloma: a case report and review of the literature. Acta Haematol 2012;128:244-7.

[27] Palladini G, Sachchithanantham S, Milani P, Gillmore J, Foli A, Lachmann H, Basset M, Hawkins P, Merlini G, Wechalekar AD. A European collaborative study of cyclophosphamide, bortezomib, and dexamethasone in upfront treatment of systemic AL amyloidosis. Blood 2015;126:612-5.

[28] Sanchorawala V, Quillen K, Sloan JM, Andrea NT, Seldin DC. Bortezomib and high-dose melphalan conditioning for stem cell transplantation for AL amyloidosis: a pilot study. Haematologica 2011;96:1890-1892.

[29] Sanchorawala V, Brauneis D, Shelton AC, Lo S, Sun F, Sloan JM, Quillen K, Seldin DC. Induction therapy with bortezomib followed by bortezomib-high dose melphalan and stem 
cell transplantation for light chain amyloidosis: results of a prospective clinical trial. Biol Blood Marrow Transplant 2015;21:1445-51.

[30] Huang X, Wang Q, Chen W, Zeng C, Chen Z, Gong D, Zhang H, Liu Z. Induction therapy with bortezomib and dexamethasone followed by autologous stem cell transplantation versus autologous stem cell transplantation alone in the treatment of renal AL amyloidosis: a randomized controlled trial. BMC Med 2014;12:2.

[31] Landau H, Hassoun H, Bello C, Hoover E, Riedel ER, Nimer SD, Comenzo RL. Consolidation with bortezomib and dexamethasone following risk-adapted melphalan and stem cell transplant in systemic AL amyloidosis. Amyloid 2011;18 Suppl 1:135-6.

[32] Landau H, Hassoun H, Rosenzweig MA, Maurer M, Liu J, Flombaum C, Bello C, Hoover E, Riedel E, Giralt S, Comenzo RL. Bortezomib and dexamethasone consolidation following risk-adapted melphalan and stem cell transplantation for patients with newly diagnosed lightchain amyloidosis. Leukemia 2013;27:823-8.

[33] Cornell RF, Zhong X, Arce-Lara C, Atallah E, Blust L, Drobyski WR, Fenske TS, Pasquini MC, Rizzo JD, Saber W, Hari PN. Bortezomib-based induction for transplant ineligible AL amyloidosis and feasibility of later transplantation. Bone Marrow Transplant 2015;50:914917.

[34] Sanchorawala V, Palladini G, Kukreti V, Zonder JA, Cohen AD, Seldin DC, Dispenzieri A, Jaccard A, Schönland SO, Berg D, Yang H, Gupta N, Hui AM, Comenzo RL, Merlini G. A phase $1 / 2$ study of the oral proteasome inhibitor ixazomib in relapsed or refractory $\mathrm{AL}$ amyloidosis. Blood 2017;130:597-605.

[35] https://clinicaltrials.gov/ct2/show/NCT01659658

[36] Cohen AD, Landau H, Scott EC, et al. Safety and efficacy of carfilzomib (CFZ) in previouslytreated systemic light-chain (AL) amyloidosis [abstract]. Blood 2016;128:645 
[37] Jelinek T, Kufova Z, Hajek R. Immunomodulatory drugs in AL amyloidosis. Crit Rev Oncol Hematol 2016;99:249-60.

[38] Zhu YX, Kortuem KM, Stewart AK. Molecular mechanism of action of immune-modulatory drugs thalidomide, lenalidomide and pomalidomide in multiple myeloma. Leuk Lymphoma 2013;54:683-7.

[39] Venner CP, Gillmore JD, Sachchithanantham S, Mahmood S, Lane T, Foard D, Rannigan L, Gibbs SD, Pinney JH, Whelan CJ, Lachmann HJ, Hawkins PN, Wechalekar AD. A matched comparison of cyclophosphamide, bortezomib and dexamethasone (CVD) versus risk-adapted cyclophosphamide, thalidomide and dexamethasone (CTD) in AL amyloidosis. Leukemia 2014;28:2304-10.

[40] Specter R, Sanchorawala V, Seldin DC, Shelton A, Fennessey S, Finn KT, Zeldis JB, Dember LM. Kidney dysfunction during lenalidomide treatment for AL amyloidosis. Nephrol Dial Transplant 2011;26:881-6.

[41] Tapan U, Seldin DC, Finn KT, Fennessey S, Shelton A, Zeldis JB, Sanchorawala V. Increases in B-type natriuretic peptide (BNP) during treatment with lenalidomide in AL amyloidosis. Blood 2010;116:5071-2.

[42] Palladini G, Milani P, Foli A, Basset M, Russo F, Perlini S, Merlini G. A phase 2 trial of pomalidomide and dexamethasone rescue treatment in patients with AL amyloidosis. Blood 2017; 129:2120-2123.

[43] Browning S, Quillen K, Sloan JM, Doros G, Sarosiek S, Sanchorawala V. Hematologic relapse in $\mathrm{AL}$ amyloidosis after high-dose melphalan and stem cell transplantation. Blood 2017; 130:1383-1386.

[44] Cheson BD, Rummel MJ. Bendamustine: rebirth of an old drug. J Clin Oncol 2009;27:1492501. 
[45] Milani P, Schönland S, Palladini G, Kimmich C, Basset M, Russo F, Foli A, Perlini S, Bochtler T, Ho AD, Merlini G, Hegenbart U. Response to bendamustine is associated with a survival advantage in a heavily pretreated patients with $\mathrm{AL}$ amyloidosis. Amyloid 2017;24:56-57.

[46] https://clinicaltrials.gov/ct2/show/NCT01222260

[47] Touzeau C, Moreau P. Daratumumab for the treatment of multiple myeloma. Expert Opin Biol Ther 2017; 17:887-893.

[48] Sher T, Fenton B, Akhtar A, Gertz MA. First report of safety and efficacy of daratumumab in 2 cases of advanced immunoglobulin light chain amyloidosis. Blood 2016;128:1987-1989.

[49] Kaufman GP, Schrier SL, Lafayette RA, Arai S, Witteles RM, Liedtke M. Daratumumab yields rapid and deep hematologic responses in patients with heavily pretreated AL amyloidosis. Blood 2017;130:900-902.

[50] Dykxhoorn DM, Lieberman J. The silent revolution: RNA interference as basic biology, research tool, and therapeutic. Annu Rev Med 2005; 56: 401-423.

[51] Hovey BM, Ward JE, Soo Hoo P, O'Hara CJ, Connors LH, Seldin DC. Preclinical development of siRNA therapeutics for AL amyloidosis. Gene Ther 2011;18:1150-6.

[52] Cooley CB, Ryno LM, Plate L, Morgan GJ, Hulleman JD, Kelly JW, Wiseman RL. Unfolded protein response activation reduces secretion and extracellular aggregation of amyloidogenic immunoglobulin light chain. Proc Natl Acad Sci USA 2014;111:13046-51.

[53] Chen JJ, Genereux JC, Qu S, Hulleman JD, Shoulders MD, Wiseman RL. ATF6 activation reduces the secretion and extracellular aggregation of destabilized variants of an amyloidogenic protein. Chem Biol 2014;21:1564-74.

[54] Plate L, Cooley CB, Chen JJ, Paxman RJ, Gallagher CM, Madoux F, Genereux JC, Dobbs W, Garza D, Spicer TP, Scampavia L, Brown SJ, Rosen H, Powers ET, Walter P, Hodder P, 
Wiseman RL, Kelly JW. Small molecule proteostasis regulators that reprogram the ER to reduce extracellular protein aggregation. Elife 2016;5.

[55] Leung N, Thomé SD, Dispenzieri A. Venetoclax induced a complete response in a patient with immunoglobulin light chain amyloidosis plateaued on cyclophosphamide, bortezomib and dexamethasone. Haematologica. 2018;103:e135-e137

[56] Shi J, Guan J, Jiang B, Brenner DA, Del Monte F, Ward JE, Connors LH, Sawyer DB, Semigran MJ, Macgillivray TE, Seldin DC, Falk R, Liao R. Amyloidogenic light chains induce cardiomyocyte contractile dysfunction and apoptosis via a non-canonical p38alpha MAPK pathway. Proc Natl Acad Sci USA 2010;107:4188-93.

[57] Mishra S, Guan J, Plovie E, Seldin DC, Connors LH, Merlini G, Falk RH, MacRae CA, Liao R. Human amyloidogenic light chain proteins result in cardiac dysfunction, cell death, and early mortality in zebrafish. Am J Physiol Heart Circ Physiol 2013;305:H95-103.

[58] Diomede L, Rognoni P, Lavatelli F, Romeo M, del Favero E, Cantù L, Ghibaudi E, di Fonzo A, Corbelli A, Fiordaliso F, Palladini G, Valentini V, Perfetti V, Salmona M, Merlini G. A Caenorhabditis elegans-based assay recognizes immunoglobulin light chains causing heart amyloidosis. Blood 2014;123:3543-52.

[59] Merlini G, Ascari E, Amboldi N, Bellotti V, Arbustini E, Perfetti V, Ferrari M, Zorzoli I, Marinone MG, Garini P, et al. Interaction of the anthracycline 4'-iodo-4'-deoxydoxorubicin with amyloid fibrils: inhibition of amyloidogenesis. Proc Natl Acad Sci USA 1995;92:295963.

[60] Cardoso I, Merlini G, Saraiva MJ. 4'-iodo-4'-deoxydoxorubicin and tetracyclines disrupt transthyretin amyloid fibrils in vitro producing noncytotoxic species: screening for TTR fibril disrupters. FASEB J 2003;17:803-9. 
[61] Ward JE, Ren R, Toraldo G, Soohoo P, Guan J, O'Hara C, Jasuja R, Trinkaus-Randall V, Liao R, Connors LH, Seldin DC. Doxycycline reduces fibril formation in a transgenic mouse model of AL amyloidosis. Blood 2011;118:6610-7.

[62] Kumar SK, Dispenzieri A, Lacy MQ, Hayman SR, Buadi FK, Dingli D et al. Doxycycline used as post transplant antibacterial prophylaxis improves survival in patients with light chain amyloidosis undergoing autologous stem cell transplantation. Blood 2012;120:3138 (abstract).

[63] Wechalekar AD, Whelan C. Encouraging impact of doxycycline on early mortality in cardiac light chain (AL) amyloidosis. Blood Cancer J 2017;7:e546.

[64] https://clinicaltrials.gov/ct2/show/NCT01677286

[65] https://clinicaltrials.gov/ct2/show/NCT02207556

[66] https://clinicaltrials.gov/ct2/show/NCT03474458

[67] https://clinicaltrials.gov/ct2/show/NCT03401372

[68] Ehrnhoefer DE, Bieschke J, Boeddrich A, Herbst M, Masino L, Lurz R, Engemann S, Pastore A, Wanker EE. EGCG redirects amyloidogenic polypeptides into unstructured, off-pathway oligomers. Nat Struct Mol Biol 2008;15:558-66.

[69] Andrich K, Hegenbart U, Kimmich C, Kedia N, Bergen HR 3rd, Schönland S, Wanker E, Bieschke J. Aggregation of full-length immunoglobulin light chains from systemic light chain amyloidosis (al) patients is remodeled by epigallocatechin-3-gallate. J Biol Chem $2017 ; 292: 2328-2344$.

[70] Mereles D, Buss SJ, Hardt SE, Hunstein W, Katus HA. Effects of the main green tea polyphenol epigallocatechin-3-gallate on cardiac involvement in patients with $\mathrm{AL}$ amyloidosis. Clin Res Cardiol 2010;99:483-90. 
[71] Meshitsuka S, Shingaki S, Hotta M, Goto M, Kobayashi M, Ukawa Y, Sagesaka YM, Wada Y, Nojima M, Suzuki K. Phase 2 trial of daily, oral epigallocatechin gallate in patients with lightchain amyloidosis. Int J Hematol 2017;105:295-308.

[72] https://clinicaltrials.gov/ct2/show/NCT02015312

[73] https://clinicaltrials.gov/ct2/show/NCT01511263

[74] Guan J, Mishra S, Qiu Y, Shi J, Trudeau K, Las G, Liesa M, Shirihai OS, Connors LH, Seldin DC, Falk RH, MacRae CA, Liao R. Lysosomal dysfunction and impaired autophagy underlie the pathogenesis of amyloidogenic light chain-mediated cardiotoxicity. EMBO Mol Med 2014;6:1493-507.

[75] Dispenzieri A, Merlini G. Immunoglobulin light chain systemic amyloidosis. Cancer Treat Res 2016;169:273-318.

[76] Bodin K, Ellmerich S, Kahan MC, Tennent GA, Loesch A, Gilbertson JA, Hutchinson WL, Mangione PP, Gallimore JR, Millar DJ, Minogue S, Dhillon AP, Taylor GW, Bradwell AR, Petrie A, Gillmore JD, Bellotti V, Botto M, Hawkins PN, Pepys MB. Antibodies to human serum amyloid P component eliminate visceral amyloid deposits. Nature 2010;468:93-7.

[77] Pepys MB, Herbert J, Hutchinson WL, Tennent GA, Lachmann HJ, Gallimore JR, Lovat LB, Bartfai T, Alanine A, Hertel C, Hoffmann T, Jakob-Roetne R, Norcross RD, Kemp JA, Yamamura K, Suzuki M, Taylor GW, Murray S, Thompson D, Purvis A, Kolstoe S, Wood SP, Hawkins PN. Targeted pharmacological depletion of serum amyloid P component for treatment of human amyloidosis. Nature 2002;417:254-9.

[78] Gillmore JD, Tennent GA, Hutchinson WL, Gallimore JR, Lachmann HJ, Goodman HJ, Offer M, Millar DJ, Petrie A, Hawkins PN, Pepys MB. Sustained pharmacological depletion of serum amyloid $\mathrm{P}$ component in patients with systemic amyloidosis. $\mathrm{Br} \mathrm{J}$ Haematol 2010;148:760-7. 
[79] Bodin K, Ellmerich S, Kahan MC, Tennent GA, Loesch A, Gilbertson JA, Hutchinson WL, Mangione PP, Gallimore JR, Millar DJ, Minogue S, Dhillon AP, Taylor GW, Bradwell AR, Petrie A, Gillmore JD, Bellotti V, Botto M, Hawkins PN, Pepys MB. Antibodies to human serum amyloid P component eliminate visceral amyloid deposits. Nature 2010;468:93-7.

[80] Richards DB, Cookson LM, Berges AC, Barton SV, Lane T, Ritter JM, Fontana M, Moon JC, Pinzani M, Gillmore JD, Hawkins PN, Pepys MB. Therapeutic clearance of amyloid by antibodies to serum amyloid P component. N Engl J Med 2015;373:1106-14.

[81] Richards DB, Cookson LM, Barton SV, Liefaard L, Lane T, Hutt DF, Ritter JM, Fontana M, Moon JC, Gillmore JD, Wechalekar A, Hawkins PN, Pepys MB. Repeat doses of antibody to serum amyloid $\mathrm{P}$ component clear amyloid deposits in patients with systemic amyloidosis. Sci Transl Med 2018;10.

[82] Wall JS, Kennel SJ, Williams A, Richey T, Stuckey A, Huang Y, Macy S, Donnell R, Barbour R, Seubert P, Schenk D. AL amyloid imaging and therapy with a monoclonal antibody to a cryptic epitope on amyloid fibrils. PLoS One 2012;7:e52686.

[83] Gertz MA, Landau H, Comenzo RL, Seldin D, Weiss B, Zonder J, Merlini G, Schönland S, Walling J, Kinney GG, Koller M, Schenk DB, Guthrie SD, Liedtke M. First-in-human phase I/II study of NEOD001 in patients with light chain amyloidosis and persistent organ dysfunction. J Clin Oncol 2016;34:1097-103.

[84] clinicaltrials.gov/ct2/show/NCT02312206

[85] http://ir.prothena.com/releasedetail.cfm?releaseid=1064584

[86] Rubinow A, Skinner M, Cohen AS. Digoxin sensitivity in amyloid cardiomyopathy. Circulation 1981;63:1285-8. 
[87] Muchtar E, Gertz MA, Kumar SK, Lin G, Boilson B, Clavell A, Lacy MQ, Buadi FK,Hayman SR, Kapoor P, Dingli D, Rajkumar SV, Dispenzieri A, Grogan M. Digoxin use in systemic light-chain (AL) amyloidosis: contra-indicated or cautious use? Amyloid. 2018:1-7.

[88] Barbhaiya CR, Kumar S, Baldinger SH, Michaud GF, Stevenson WG, Falk R, John RM. Electrophysiologic assessment of conduction abnormalities and atrial arrhythmias associated with amyloid cardiomyopathy. Heart Rhythm 2016;13:383-90.

[89] Sayed RH, Rogers D, Khan F, Wechalekar AD, Lachmann HJ, Fontana M, Mahmood S, Sachchithanantham S, Patel K, Hawkins PN, Whelan CJ, Gillmore JD. A study of implanted cardiac rhythm recorders in advanced cardiac AL amyloidosis. Eur Heart J 2015;36:1098105.

[90] Hamon D, Algalarrondo V, Gandjbakhch E, Extramiana F, Marijon E, Elbaz N, Selhane D, Dubois-Rande JL, Teiger E, Plante-Bordeneuve V, Damy T, Lellouche N. Outcome and incidence of appropriate implantable cardioverter-defibrillator therapy in patients with cardiac amyloidosis. Int J Cardiol 2016;222:562-8.

[91] Rezk T, Whelan CJ, Lachmann HJ, Fontana M, Sachchithanantham S, Mahmood S, Khan F, Khiani R, Tomson J, Youngstein T, Gillmore JD, Hawkins PN, Wechalekar AD. Role of implantable intracardiac defibrillators in patients with cardiac immunoglobulin light chain amyloidosis. Br J Haematol 2017 May 9 [Epub ahead of print]

[92] Kristen AV, Dengler TJ, Hegenbart U, Schonland SO, Goldschmidt H, Sack FU, Voss F, Becker R, Katus HA, Bauer A. Prophylactic implantation of cardioverter-defibrillator in patients with severe cardiac amyloidosis and high risk for sudden cardiac death. Heart Rhythm 2008;5:235-40. 
[93] Varr BC, Zarafshar S, Coakley T, Liedtke M, Lafayette RA, Arai S, Schrier SL, Witteles RM. Implantable cardioverter-defibrillator placement in patients with cardiac amyloidosis. Heart Rhythm 2014;11:158-62.

[94] Sayed RH, Rogers D, Khan F, Wechalekar AD, Lachmann HJ, Fontana M, Mahmood S, Sachchithanantham S, Patel K, Hawkins PN, Whelan CJ, Gillmore JD. A study of implanted cardiac rhythm recorders in advanced cardiac AL amyloidosis. Eur Heart J. 2015;36:1098105.

[95] Swiecicki PL, Edwards BS, Kushwaha SS, Dispenzieri A, Park SJ, Gertz MA. Left ventricular device implantation for advanced cardiac amyloidosis. J Heart Lung Transplant 2013;32:5638.

[96] Varr BC, Liedtke M, Arai S, Lafayette RA, Schrier SL, Witteles RM. Heart transplantation and cardiac amyloidosis: approach to screening and novel management strategies. J Heart Lung Transplant 2012;31:325-31.

[97] Davis MK, Kale P, Liedtke M, Schrier S, Arai S, Wheeler M, Lafayette R, Coakley T, Witteles RM. Outcomes after heart transplantation for amyloid cardiomyopathy in the modern era. Am J Transplant 2015;15:650-8.

[98] Mehra MR, Canter CE, Hannan MM, Semigran MJ, Uber PA, Baran DA, Danziger-Isakov L, Kirklin JK, Kirk R, Kushwaha SS, Lund LH, Potena L, Ross HJ, Taylor DO, Verschuuren EA, Zuckermann A; International Society for Heart Lung Transplantation (ISHLT) Infectious Diseases Council; International Society for Heart Lung Transplantation (ISHLT) Pediatric Transplantation Council; International Society for Heart Lung Transplantation (ISHLT) Heart Failure and Transplantation Council. The 2016 International Society for Heart Lung Transplantation listing criteria for heart transplantation: A 10-year update. J Heart Lung Transplant. 2016;35:1-23. 
[99] Merlini G, Comenzo RL, Seldin DC, Wechalekar A, Gertz MA. Immunoglobulin light chain amyloidosis. Expert Rev Hematol 2014;7:143-56.

[100] Le Bras F, Molinier-Frenkel V, Guellich A, Dupuis J, Belhadj K, Guendouz S, Ayad K, Colombat M, Benhaiem N, Tissot CM, Hulin A, Jaccard A, Damy T. Sequential cyclophosphamide-bortezomib-dexamethasone unmasks the harmful cardiac effect of dexamethasone in primary light-chain cardiac amyloidosis. Eur J Cancer 2017;76:183-187. 